\title{
Effectiveness of herbal oral care products in reducing dental plaque \& gingivitis - a systematic review and meta-analysis
}

\author{
Chandrashekar Janakiram ${ }^{1}$ (D, Ramanarayanan Venkitachalam², Paul Fontelo ${ }^{3}$, Timothy J. lafolla ${ }^{4}$ and Bruce A. Dye ${ }^{4^{*}}$ (D)
}

\begin{abstract}
Background: Despite the large number of trials conducted using herbal oral care products for the reduction of dental plaque or gingivitis, results are conflicting and inconclusive.

Objective: To assess the effectiveness of herbal oral care products compared to conventional products in reducing dental plaque and gingivitis adults.

Methods: We searched the following databases for Randomised controlled trials (RCTs): MEDLINE Ovid, EMBASE Ovid etc. which yielded 493 trails. Of which 24 RCTs comparing herbal toothpaste or mouth rinse with over the counter toothpaste or mouth rinse in adults aged 18 to 65 years were included. Two authors extracted information and assessed the methodological quality of the included studies using Risk of Bias. Meta-analyses using the random-effects model were conducted for four outcomes for tooth paste and mouth rinse respectively. Mean difference (MD) or standardized mean difference (SMD) were used to estimate the effect, with 95\% confidence intervals.
\end{abstract}

Results: A total of 1597 adults participated in 24 RCT studies. These were classified as herbal toothpaste (HTP) (15 trials, 899 participants) and herbal mouth rinse (HMR) (9 trials, 698 participants) compared with non-herbal toothpaste (NHTP) or nonherbal mouth rinse (NHMR). We found that HTP was superior over NHTP (SMD 1.95, 95\% Cl (0.97-2.93)) in plaque reduction. The long-term use of NHMR was superior in reduction of dental plaque over HMR (SMD -2.61, 95\% (Cl 4.42-0.80)). From subgroup analysis it showed that HTP was not superior over fluoride toothpaste (SMD 0.99, 95\% Cl (0.14-2.13)) in reducing dental plaque. However, HTP was favoured over non-fluoride toothpaste (SMD 4.64, 95\% Cl (2.23-7.05)).

Conclusion: For short-term reduction in dental plaque, current evidence suggests that HTP is as effective as compared to NHTP; however, evidence is from low quality studies.

Keywords: Toothpastes, Dentifrices, Mouthwashes, Fluoride dental plaque, Herbal

\section{Introduction}

The effective removal of dental plaque is important for maintaining periodontal and oral health [1]. Although mechanical control of microbial plaque by self-care efforts is important to prevent the plaque accumulation, this alone will not suffice. Chemical control of dental plaque is an adjunct therapy which may facilitate the removal and prevent the accumulation of microbial plaque, potentially reducing the dependence on mechanical oral care behaviours [2]. Consequently, the use of

\footnotetext{
* Correspondence: bruce.dye@nih.gov

${ }^{4}$ National Institute of Dental and Craniofacial Research, 31 Center Drive, Bethesda, MD 20892-2190, USA

Full list of author information is available at the end of the article
}

both chemical and mechanical plaque control is recommended for optimal oral hygiene $[3,4]$.

Various chemical agents have been used in toothpastes and mouth rinses and a few have been shown to reduce dental plaque formation [5, 6]. Due to an increased awareness of indigenous medical practices in various parts of the world, the use of "herbal" medicine has engendered interest and facilitated the growth of complementary and alternative therapies in health care promotion. Herbal ingredients have been present in oral care products, more commonly in South Asian countries, for some time [7-9]. The most common herbal ingredients to be incorporated into oral care products (e.g., toothpaste and mouth rinse) are sanguinarine, propolis, Azadirachta indica (neem), charcoal, 
clove, and miswak [10]. In the rural regions of South Asian countries, use of natural products like neem twigs, charcoal powder, and others have been an important part of regular oral hygiene practice for centuries. Many of the herbal or plant extracts have been promoted as possessing antiinflammatory, antipyretic, analgesic, antibacterial, antiviral, anticarcinogenic and antioxidant activities by means of in vitro, in vivo, and animal studies $[10,11]$.

Based on these observations, several oral care product manufacturers and multinational companies have incorporated herbal ingredients into their products. Manufacturers of these products use a wide range of herbal ingredients which they claim mimic the benefits of traditional toothpastes - the ability to fight plaque, freshen breath and prevent gum disease. The tendency to "go natural" has fuelled an increase in demand for such products by consumers with many apparently opting for them because they are not tested on animals, carry no side effects, use no animal products, are vegan friendly, contains no added artificial colours or flavours, and for cultural reasons. In some regions, sale of herbal products outnumbers fluoride-based toothpastes [12] .

Comparison between herbal and conventional oral care products for the reduction of dental plaque or gingivitis were tested in clinical trials. Despite the large number of trials conducted, results are conflicting and inconclusive. Some of these products were approved by dental associations in some countries. Existing literature reviews are primarily narrative or based on single herbal ingredient (e.g., Aloe vera) in mouth rinse or toothpaste [13-16]. There is not a single, comprehensive systematic review which synthesized the current evidence for assessing effectiveness in reducing dental plaque and gingivitis using herbal oral care products such as herbal toothpaste (HTP) and herbal mouth rinse (HMR). Therefore, the objective of this study is to systematically assess the literature and quantitatively measure the effectiveness of herbal toothpaste and mouth rinse compared to conventional over the counter (OTC) products in reducing dental plaque and gingival inflammation in adults.

\section{Materials and methods}

This systematic review was conducted following the preferred reporting items for systematic reviews and metaanalyses (PRISMA) statement and the patient, intervention, comparison, outcomes (PICO) method as applicable in relation to the topic of the review:

Patient: adults $>18$ years.

Intervention: Herbal Toothpastes or Mouth rinses.

Comparison: Over the counter (OTC) non-herbal oral care products (Fluoride toothpaste, Non-fluoride/ Non-herbal toothpaste, Chlorhexidine mouth rinse or non-herbal Mouth rinse).

Outcomes: Reduction in dental plaque levels and gingival inflammation.
Focused question: Are the herbal care products (toothpaste and mouth rinse) non-inferior in reduction of dental plaque and gingival inflammation over the commercial over the counter (OTC) products in adults?

\section{Eligibility criteria}

This systematic review was limited to randomized controlled trials with parallel arm design (RCTs) where randomization occurred at the level of the individual. Quasi-randomized trials were excluded. Included studies were those with participants who were adults $>18$ years with no other restrictions on age or gender nor study conduct in any country. The intervention group consisted of subjects using herbal oral care products (either toothpaste or mouth rinse) which had an active herbal ingredient, or a natural or plant extract as claimed by the manufacturer. The control group consisted of subjects (active controls) using formulation containing nonherbal active ingredients in toothpaste and mouth rinse that were commercially available OTC or manufactured as placebos for the study.

\section{Outcomes}

The following outcomes were assessed for both the intervention arm (HMR and/or HTP) and the control arm of the studies:

1. Mean reduction in the plaque measure by Silness and Loe Plaque index or modified Quigley Hein plaque index;

2. Mean reduction of the gingival inflammation by Loe and Silness Gingival index;

3. Short-term effects (studies with 4-week follow-up acceptability range \pm 3 days)

4. Long-term effects (studies with 12-weeks follow-up acceptability range \pm 3 days)

\section{Information sources and search}

The electronic search was performed with the databases MEDLINE Ovid, EMBASE Ovid, WHO clinical trial register, ClinicalTrials.gov and Cochrane Library, with a platform-specific search strategy consisting of combinations of controlled terms (MeSH) and text words. A copy of the detailed search strategy for MEDLINE Ovid is included in Additional file 1: Table S1. Additionally, the bibliographies of retrieved articles were reviewed. The search strategy terms included "herbal mouth rinses" or herbal tooth pastes" with no language restrictions. Two authors (C) and $\mathrm{RV}$ ) independently eliminated any duplicate from the gathered results and examined the remaining articles by title and abstract. Subsequently, the full texts were obtained and analysed for further inclusion/exclusion. Studies that did not meet the inclusion criteria were excluded. The article full-text of those identified after the title and 
abstract were screened. The search was performed on June 2018 for all mentioned databases. There was no lower limit for the analysed time frame.

\section{Data collection process and data items}

For every included study, using Microsoft Excel sheet, the participant study definition, risk of bias assessment, total length of the study, unit of randomization, unit of analysis, participants' characteristics, interventions, outcomes, results and other items were collected for each study by two reviewers. The treatment effect for each study was summarized using mean differences and standard deviations (SD). The standardized weighted-mean differences (SMD) were calculated for outcomes (measured by different scales/indices) for each study. Random-effects models [17] were used to calculate a pooled estimate of effect and its $95 \%$ confidence intervals (CIs). Authors were contacted in the event of missing data. Non-reported SDs were calculated from the reported standard errors, confidence intervals, presented for mean differences. Data were analysed with RevMan 5.3.

\section{Assessment of risk of bias}

The risk of bias assessment of the included studies used the approach recommended by with the Cochrane Collaboration's tool [18]. All included studies were assessed independently and in duplicate by two review authors (C) and RV) for study design characteristics and features of internal validity. Assessment was done within and across studies. The first step was writing a description of the results of each included study. Next, involved was the assessment of the risk of bias where a score of low, high, or unclear was assigned for each included study. The overall quality of each study was then assessed by grading the 7 bias categories. A score of 3,1 , and 0 were considered as low, unclear, and high risk of bias respectively for each of the seven categories of biases. The scores were averaged for each included study and results are provided in the Table 1. Review authors were not blinded to author and source institution. Any disagreement was resolved by discussion or by third party adjudication.

\section{Synthesis of results}

We performed an evaluation of the heterogeneity of the data using Cochran's Q statistic, a chi-square test, a threshold $p$-value of less than 0.10 [19]. The consistency of the results was assessed visually using forest plots and by the $\mathrm{I}^{2}$ statistic [20]. The $\mathrm{I}^{2}$ statistic describes the proportion of variation in point estimates attributable to heterogeneity as compared to sampling error. Subgroup analyses were performed to assess the impact of the HTP on duration of intervention ( 4 vs. 12 weeks). Forest plots were used for graphic presentation. A 'Summary of Findings' Table 2 used the GRADE Profiler software (version 3.6) for the primary outcomes [21].

\section{Results}

\section{Study selection}

Electronic searches from all sources retrieved 493 citations (Fig. 1). Using titles and abstracts to screen content, 305 citations were excluded duplications. 126 articles were excluded due to non-clinical studies in humans or were reviews or opinion papers. Out of 62 clinical trials, 38 did not meet the inclusion criteria [measured other outcomes [9], follow up period variation [16], variation in RCT design [3], missing values of outcome [6], variation in index used for plaque assessment [1] and full text was not available for two articles] (See Additional file 1: Table S2 for list of excluded trials and reasons). Most studies originated from Southeast Asia and all were in the English language.

\section{Study description}

The 24 RCTs comprising 1597 adults (899 HTP participants and 698 HMR participants) for inclusion in the summary analyses. Selected characteristics of the included studies are shown in Table 1 . There were 15 HTP and 9 HMR trials using non-herbal toothpaste (NHTP) or non-herbal mouth rinse (NHMR) as the control arm. Eleven HTP studies [9, 22-31] assessed short-term effects (4-weeks follow up) on dental plaque reduction whereas four studies [31-34] assessed for long-term effects (12-weeks follow up). Ten HTP studies [7, 9, 22-27, 30, 31] assessed short-term effects (4 weeks follow up) on gingival inflammation reduction whereas three studies [31-33] assessed long-term effects. Among the HTP studies, seven and eight studies assessed short-term effects on dental plaque reduction and gingival inflammation reduction, respectively, with fluoridated toothpaste as the control. Six HMR trials each assessed shortterm [35-39] and long-term effects [36, 37, 40-42] on dental plaque reduction. Six studies assessed short-term effects on gingival inflammation [35-39] reduction whereas five studies assessed for long-term effects [36, 37, 41, 42].

There was clinical heterogeneity in the herbal ingredients present in toothpastes studied. Four studies [7, 22, 25, 31] assessed chamomile (Matricaria recutita), two studies evaluated neem (Azadirachta indica) [9, 30], Aloe vera (Aloe barbadensis) [23,33] and calendula (Calendula officinalis) $[26,32]$ respectively. Individual studies for salvoadoral persica [29], chitosan [28], ajamoda satva (Apium graveolens) [24], lippia sidiodes (Pepper-rosmarin) [34] and vaikrantha bhasma (Dolichos biflorus) were also conducted [27]. Eight HTP studies [22-25, 27, 30-32] used fluoride as the control, whereas four studies [26, 28, 33, 34] used placebo with the rest using non-herbal, non-fluoride OTC toothpastes. Six studies $[9,23,26-28,32]$ assessed dental plaque using the Silness and Löe Plaque Index [43] whereas eight studies $[22,24,25,29-31,33,34]$ assessed dental plaque using the Turesky-Gilmore modification of the Quigley Hein Plaque 
Table 1 Summary characteristics of included studies

\begin{tabular}{|c|c|c|c|c|c|c|c|}
\hline \multirow[t]{2}{*}{ SI No. } & \multirow[t]{2}{*}{ Study ID } & \multirow[t]{2}{*}{ Country } & \multirow{2}{*}{$\begin{array}{l}\text { Intervention- } \\
\text { Herbal }\end{array}$} & \multirow[t]{2}{*}{ Control } & \multicolumn{2}{|c|}{ Index used* } & \multirow{2}{*}{$\begin{array}{l}\text { Average Score o } \\
\text { Quality of study }\end{array}$} \\
\hline & & & & & Plaque & Gingival & \\
\hline \multicolumn{8}{|c|}{ TOOTHPASTE STUDIES } \\
\hline 1 & Abhishek 2015 & India & Azadirachta indica & non-herbal & PSL & GLS & 16 \\
\hline 2 & Al-Kholani 2011 & Yemen & camomile & conventional & - & GLS & 9 \\
\hline 3 & Amoain 2010 & Iran & calendula & placebo & PSL & GLS & 17 \\
\hline 4 & Amrutesh 2010 & India & vaikrantha & fluoride & PSL & GLS & 17 \\
\hline 5 & George 2009 & India & camomile & fluoride & $\mathrm{TQH}$ & GLS & 19 \\
\hline 6 & Gupta 2012 & India & salvadora persica & conventional & $\mathrm{TQH}$ & - & 21 \\
\hline 7 & Habashneh 2017 & Jordan & camomile & fluoride & $\mathrm{TQH}$ & GLS & 14 \\
\hline 8 & Mohire 2010 & India & chitosan & placebo & PSL & - & 6 \\
\hline 9 & Olivera 2008 & Brazil & Aloe vera & fluoride & PSL & GLS & 19 \\
\hline 10 & Ozaki 2008 & Brazil & camomile & fluoride & $\mathrm{TQH}$ & GLS & 21 \\
\hline 11 & Rao 2008 & India & pumica granatum & fluoride & $\mathrm{TQH}$ & GLS & 15 \\
\hline 12 & Tatikonda 2014 & India & azadirachta indica & fluoride & $\mathrm{TQH}$ & GLS & 16 \\
\hline 13 & Estafan 1998 & USA & calendula & fluoride & PSL & GLS & 10 \\
\hline 14 & Pereira 2013 & Brazil & lippia sidiodes & placebo & $\mathrm{TQH}$ & - & 17 \\
\hline 15 & Pradeep 2012 & India & aloe vera & placebo & $\mathrm{TQH}$ & GLS & 18 \\
\hline \multicolumn{8}{|c|}{ MOUTHRINSE STUDIES } \\
\hline 16 & Charles 2004 & USA & essential oils & chlorhexidine & $\mathrm{TQH}$ & GLS & 16 \\
\hline 17 & Jain 2017 & India & licorice & chlorhexidine & $\mathrm{TQH}$ & GLS & 9 \\
\hline 18 & Lauten 2005 & USA & maleluca & chlorhexidine & PSL & GLS & 13 \\
\hline 19 & Pourabbas 2005 & Iran & camomile & chlorhexidine & $\mathrm{TQH}$ & GLS & 15 \\
\hline 20 & Ratika 2014 & India & azadirachta indica & chlorhexidine & PSL & GLS & 16 \\
\hline 21 & Ratika [2] 2014 & India & mango & chlorhexidine & PSL & GLS & 16 \\
\hline 22 & Shetty 2013 & India & azadirachta indica & chlorhexidine & $\mathrm{TQH}$ & GLS & 19 \\
\hline 23 & Vangipuram 2016 & India & aloe vera & chlorhexidine & PSL & GLS & 21 \\
\hline 24 & Weijden 1998 & Netherlands & juniper & placebo & PSL & GLS & 19 \\
\hline
\end{tabular}

* PSL = Silness and Loe plaque index TQH = Turesky-Gilmore modification of Quigley Hein plaque index GLS = Loe and Silness gingival index

\# Quality of score assessment: No risk - 3, Unclear risk - 1, High risk - 0 (sum of each of the seven biases were taken)

[44] Index in HTP studies. All studies assessed gingival inflammation by Silness and Löe Gingival Index [45].

Every HMR study had a different herbal ingredient, with the exception of two trials which had Neem (Azadirachta indica) as the active ingredient [36, 37]. Eight of these had chlorhexidine as the control while one had placebo. Five studies assessed dental plaque using the Silness and Löe Plaque Index whereas four studies assessed dental plaque using the Turesky-Gilmore modification of Quigley Hein Plaque Index in HMR studies. All studies assessed gingival inflammation by Silness and Löe Gingival Index. Clinical outcomes in all studies were measured as continuous variables reported as mean $\pm \mathrm{SD}$.

\section{Risk of Bias assessments}

A synthesis of the assessment of the methodological quality items (authors' judgement of risk of bias for each included study) is presented in Additional file 1:
Figure. S1. Three studies showed low risk of bias [22, $29,38]$, seven studies had unclear risk [23, 25-27, 34, $36,40]$ and the remainder were high risk. Additional file 1: Figure. S2 depicts a risk of bias graph, illustrating the authors' judgements about each risk of bias item presented as percentages across all included studies. Among all, allocation concealment or selection bias and blinding of the participants had higher proportions of bias across the studies.

\section{Synthesis of results - effect of interventions}

\section{Herbal toothpaste}

Overall, in 11 pooled studies involving 712 adults (Table 2), participants using HTP were more likely to experience a reduction in dental plaque scores during a four-week period compared to those using NHTP [SMD 1.95, 95\% CI (0.97 to 2.93)], but there was substantial heterogeneity (95\%) across 
Table 2 Summary of Findings

\begin{tabular}{|c|c|c|c|c|c|c|}
\hline Outcomes & $\begin{array}{l}\text { Intervention } \\
(\text { Mean } \pm \text { SD) }\end{array}$ & $\begin{array}{l}\text { Control } \\
(\text { Mean } \pm \text { SD) }\end{array}$ & $\begin{array}{l}\text { No of Participants } \\
\text { (studies) }\end{array}$ & $\begin{array}{l}\text { Pooled } \\
\text { Estimate }\end{array}$ & Ref & $\begin{array}{l}\text { Quality of the } \\
\text { evidence (GRADE) }\end{array}$ \\
\hline $\begin{array}{l}\text { HTP Dental Plaque. } \\
\text { Follow-up: Short } \\
\text { term }\end{array}$ & $\begin{array}{l}\text { The mean short-term effects } \\
\text { HTP in the intervention } \\
\text { groups was } 0.52 \pm 0.33\end{array}$ & $\begin{array}{l}\text { The mean short-term effects } \\
\text { of NHTP in the control } \\
\text { groups was } 0.31 \pm 0.21\end{array}$ & $\begin{array}{l}712 \\
\text { (11 studies) }\end{array}$ & $\begin{array}{l}\text { 1.95 higher } \\
(0.97,2.93)\end{array}$ & Fig. 2 A & $\begin{array}{l}\oplus \oplus \ominus \Theta \\
\text { low }\end{array}$ \\
\hline $\begin{array}{l}\text { HTP Dental Plaque. } \\
\text { Follow-up: Long } \\
\text { term }\end{array}$ & $\begin{array}{l}\text { The mean long-term effects } \\
\text { of HTP in the intervention } \\
\text { groups was } 1.02 \pm 0.68\end{array}$ & $\begin{array}{l}\text { The mean long-term effects } \\
\text { of NHTP in the control } \\
\text { groups was } 0.80 \pm 0.50\end{array}$ & $\begin{array}{l}166 \\
\text { (4 studies) }\end{array}$ & $\begin{array}{l}0.89 \text { higher } \\
(-0.93,2.72)\end{array}$ & Fig. 2 A & $\begin{array}{l}\oplus \oplus \oplus \ominus \\
\text { moderate }\end{array}$ \\
\hline $\begin{array}{l}\text { HTP Gingival } \\
\text { inflammation. } \\
\text { Follow-up: Short } \\
\text { term }\end{array}$ & $\begin{array}{l}\text { The mean short-term effects } \\
\text { of HTP in the intervention } \\
\text { groups was } 0.41 \pm 0.30\end{array}$ & $\begin{array}{l}\text { The mean short-term effects } \\
\text { of NHTP in the control } \\
\text { groups was } 0.32 \pm 0.19\end{array}$ & $\begin{array}{l}410 \\
\text { (10 studies) }\end{array}$ & $\begin{array}{l}0.09 \text { higher } \\
(-0.14,0.00)\end{array}$ & Fig. 2 B & $\begin{array}{l}\oplus \oplus \ominus \ominus \\
\text { low }\end{array}$ \\
\hline $\begin{array}{l}\text { HTP Gingival } \\
\text { Inflammation. } \\
\text { Follow-up: Long } \\
\text { term }\end{array}$ & $\begin{array}{l}\text { The mean long-term effects } \\
\text { of HTP in the intervention } \\
\text { groups was } 0.50 \pm 0.50\end{array}$ & $\begin{array}{l}\text { The mean long-term effects } \\
\text { of NHTP in the control } \\
\text { groups was } 0.43 \pm 0.24\end{array}$ & $\begin{array}{l}146 \\
\text { (3 studies) }\end{array}$ & $\begin{array}{l}0.07 \text { higher } \\
(-0.23,0.36)\end{array}$ & Fig. 2 B & $\begin{array}{l}\oplus \oplus \ominus \ominus \\
\text { low }\end{array}$ \\
\hline $\begin{array}{l}\text { HMR Dental Plaque. } \\
\text { Follow-up: Short } \\
\text { term }\end{array}$ & $\begin{array}{l}\text { The mean short-term effects } \\
\text { of HMR in the intervention } \\
\text { groups was } 0.79 \pm 0.49\end{array}$ & $\begin{array}{l}\text { The mean short-term effects } \\
\text { in of NHTP in the control } \\
\text { groups was } 0.91 \pm 0.87\end{array}$ & $\begin{array}{l}582 \\
\text { (6 studies) }\end{array}$ & $\begin{array}{l}2.93 \text { lower } \\
(-6.43,0.58)\end{array}$ & Fig. 3 A & $\begin{array}{l}\oplus \oplus \oplus \ominus \\
\text { moderate }\end{array}$ \\
\hline $\begin{array}{l}\text { HMR Dental Plaque } \\
\text { Follow-up: Long } \\
\text { term }\end{array}$ & $\begin{array}{l}\text { The mean long terms effects } \\
\text { of HMR in the intervention } \\
\text { groups was } 0.23 \pm 0.51\end{array}$ & $\begin{array}{l}\text { The mean long terms effects } \\
\text { of NHTP in the control } \\
\text { groups was } 0.33 \pm 0.49\end{array}$ & $\begin{array}{l}285 \\
\text { (5 studies) }\end{array}$ & $\begin{array}{l}2.61 \text { lower } \\
(-4.42,-0.80)\end{array}$ & Fig. 3 A & $\begin{array}{l}\oplus \oplus \oplus \ominus \\
\text { moderate }\end{array}$ \\
\hline $\begin{array}{l}\text { HMR Gingival } \\
\text { Inflammation. } \\
\text { Follow-up: } \\
\text { Short term }\end{array}$ & $\begin{array}{l}\text { The mean short-term effects } \\
\text { of HMR in the intervention } \\
\text { groups was } 0.82 \pm 0.34\end{array}$ & $\begin{array}{l}\text { The mean short-term effects } \\
\text { of NHTP in the control } \\
\text { groups was } 0.97 \pm 0.54\end{array}$ & $\begin{array}{l}582 \\
\text { (6 studies) }\end{array}$ & $\begin{array}{l}0.15 \text { lower } \\
(-0.32,0.01)\end{array}$ & Fig. 3 B & $\begin{array}{l}\oplus \oplus \ominus \ominus \\
\text { low }\end{array}$ \\
\hline $\begin{array}{l}\text { HMR Gingival } \\
\text { inflammation. } \\
\text { Follow-up: } \\
\text { Long term }\end{array}$ & $\begin{array}{l}\text { The mean long-term effects } \\
\text { of HMR in the intervention } \\
\text { groups was } 0.22 \pm 0.36\end{array}$ & $\begin{array}{l}\text { The mean long-term effects } \\
\text { of NHTP in the control } \\
\text { groups was } 0.31 \pm 0.49\end{array}$ & $\begin{array}{l}255 \\
\text { (5 studies) }\end{array}$ & $\begin{array}{l}0.09 \text { lower } \\
(-0.25,0.08)\end{array}$ & Fig. 3 B & $\begin{array}{l}\oplus \oplus \ominus \ominus \\
\text { low }\end{array}$ \\
\hline
\end{tabular}

HTP herbal toothpaste, NHTP non herbal toothpaste, HMR herbal mouthrinse, NHMR non herbal mouthrinse, Short-term effect 4 weeks, Long Term effects 12 Weeks

studies (Fig. 2-2a). However, 4 trials studying long-term effects did not favour HTP for reduction in dental plaque [SMD $0.89,95 \%$ CI (- 0.93 to 2.72$)$ ]. Regarding gingival inflammation, for both short-term [SMD 0.09, 95\% CI $(-0.14$ to 0.00$), 10$ studies] and long-term effects [SMD 0.07, 95\% CI ( -0.23 to 0.36 ), 3 studies], the pooled results did not significantly favour HTP when compared to NHTP (Fig. 2-2b).

The significant difference in Plaque Index reduction that was found at 4 weeks between HTP and NHTP was investigated with a sub group analysis. The controls (NHTP) were divided into non-fluoride toothpaste and fluoridated toothpaste.

HTP was not superior over fluoride toothpaste (SMD $0.99,95 \%$ CI -0.14 to 2.13 , 7 studies, short-term) in reducing dental plaque at 4 weeks (Fig. 3-3a). however, it was favoured to reduce dental plaque over non-fluoride toothpaste (SMD 4.64., 95\% CI (2.23, 7.05), 4studies] (Fig. 3-3b). In another subgroup analysis, HTP was favoured over NHTP when short-term studies used the Silness and Löe Index [MD 0.37, 95\% CI (0.14 to 0.59), 5 studies] in reducing dental plaque (Fig. 3-3c). There was significantly greater reduction in Plaque was observed for HTP compared to non-fluoride toothpastes, but not with fluoride toothpastes;

\section{Herbal mouth rinse}

There was no difference in mean reduction of dental plaque [SMD $-2.93,95 \%$ CI (- 6.43 to 0.58 ), 6 studies, 582 participants] by HMR compared to NHMR for short-term use (Fig. 4-4a). However, there was substantial evidence of mean reduction of dental plaque by users of NHMR compared to HMR in 6 studies [SMD $-2.61,95 \%$ CI ( -4.42 to -0.80$), 285$ participants) at 12 weeks. Regarding gingival inflammation, for both shortterm [SMD $-0.15,95 \% \mathrm{CI}(-0.32$ to 0.01$), 6$ studies] and long-term effects [SMD $-0.09,95 \% \mathrm{CI}(-0.25$ to 0.08$), 6$ studies], the pooled findings did not significantly favour NHMR when compared to HMR (Fig. 4-4b).

\section{Discussion}

Despite the fact that most individuals claim to brush their teeth at least twice a day, the prevalence of gingivitis and chronic periodontitis remains high in most populations [46]. The maintenance of an effective level of plaque control is clearly difficult using conventional mechanical procedures and dentifrices and yet, from a therapeutic perspective, it is currently the only realistic means of improving the periodontal health of populations. We assessed whether herbal toothpastes improved 


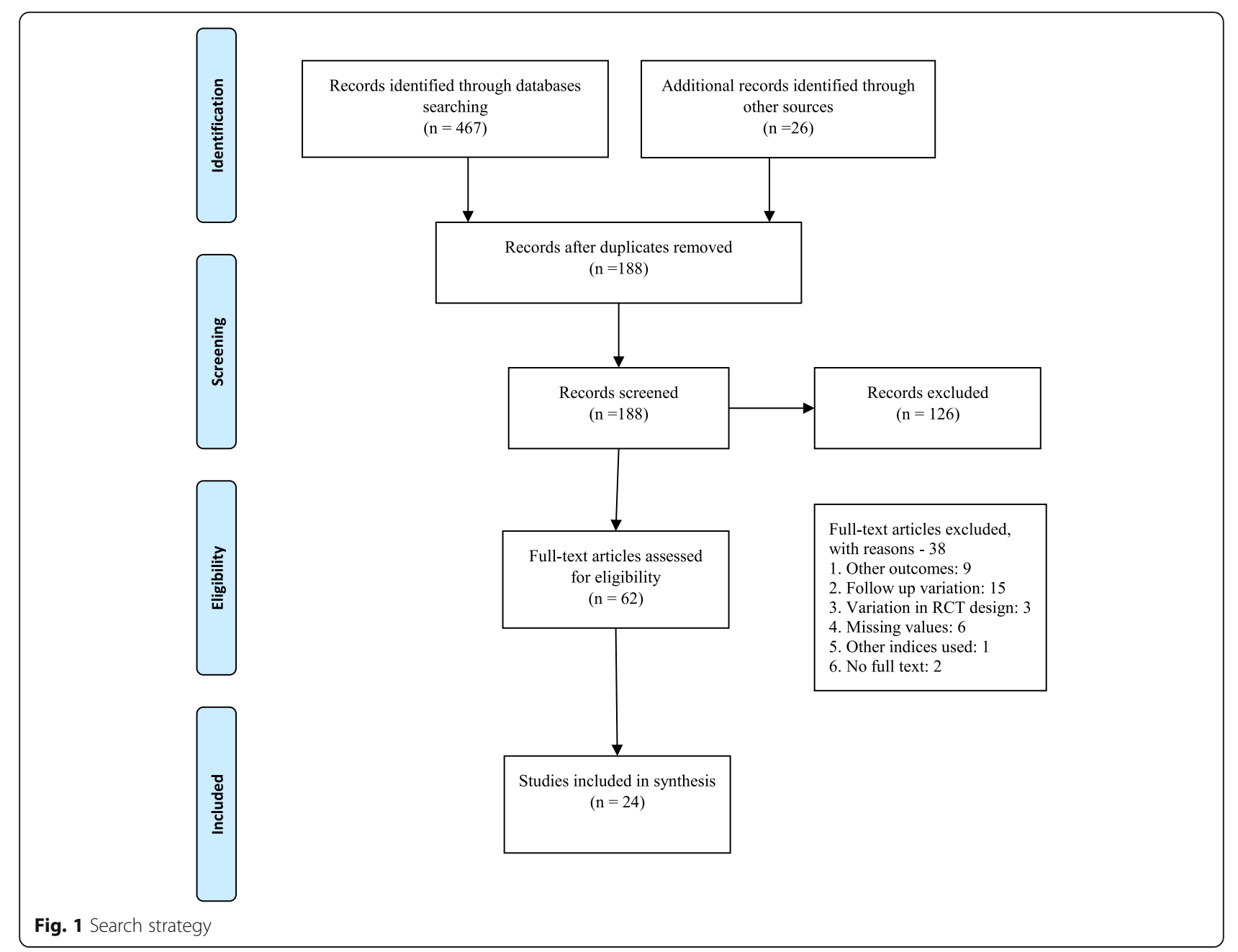

the effectiveness of plaque control and gingival health in comparison to non-herbal toothpaste. Overall, our findings suggest that HTP is superior to NHTP at removing supra-gingival plaque at short term use of 4 weeks, but there is no difference at long-term use of 12 weeks.

In this review, HTP contained a variety of herbs or plant extracts, which accounts for substantial clinical heterogeneity. The term 'herbal' is used to refer collectively to all ingredients that are botanicals or extracts and these ingredients should not be inferred as necessarily therapeutic within the composition of the product [47]. For example, if an herb like Aloe vera or neem is added to a toothpaste, the component of neem or Aloe vera which might act against the cariogenic microflora is unknown or has been isolated. Hence, it can be argued that there is a plurality of effect in herbal or botanical extracts making its action non-specific. Studies have shown that herbal extracts are indicated for their cleansing, astringent, anti-microbial, and refreshing properties which are non-specific actions in body [31, 48-51]. However, the anti-plaque efficacy or reduction of gingival inflammation by fluoride is specific to dental plaque and oral microorganisms. Therefore, it could be concluded that the herbal toothpaste may not exert significant therapeutic effects on plaque and gingivitis beyond that of a conventional commercial dentifrice.

HTP was effective in reducing dental plaque in studies having non-fluoridated toothpaste as the control, and the effect was statistically significant. Dental plaque is a significant risk factor for the development of dental caries and periodontal disease [52]. One proposed mechanism of action regarding the active ingredients of herbal dentifrices is penetration of the biofilm and prevention of plaque accumulation, thereby potentially preventing the colonization of oral bacteria on the tooth surfaces [53]. However, very few studies have evaluated the microbial efficacy of commercially available herbal dentifrices against oral microflora [26, 49]. Studies using the Silness and Löe Index for measuring dental plaque showed statistically significant plaque reduction at 4 weeks, but not at 12 weeks duration. Ideally long-term action is an important indicator of potency of the toothpaste, however, in this finding 


\section{a. Effect on plaque reduction}

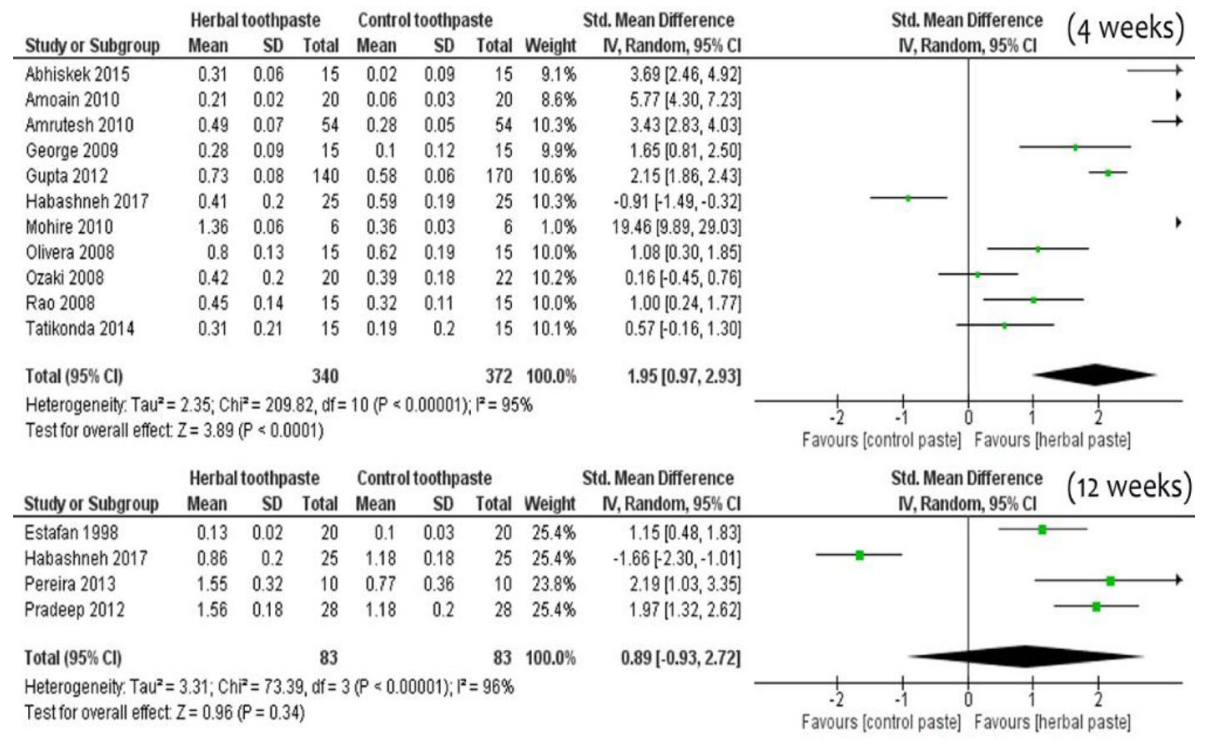

b. Effect on gingival inflammation

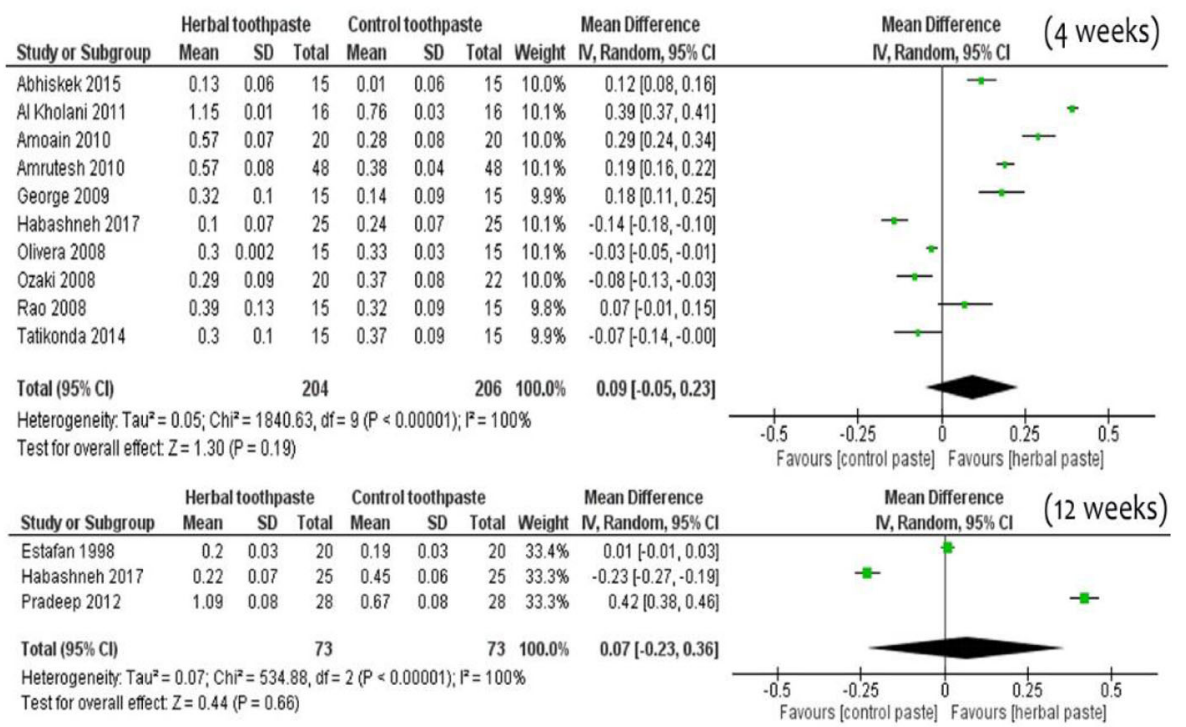

Fig. 2 Comparison of herbal toothpaste with non-herbal toothpaste (all controls) $2 \mathbf{a}$. Effect on plaque reduction $2 \mathbf{b}$. Effect on gingival inflammation

suggest, there may be methodological bias related outcome assessment measures and plurality of herbal ingredients.

There was little difference in the use of HMR compared to NHMR for reduction in dental plaque or gingival inflammation regardless of study duration. In all trials, NHMR were based on chlorhexidine, which has been proven to be a specific agent against oral microorganisms associated with dental caries and periodontal disease. There is strong evidence for the anti-plaque and antigingivitis effects of chlorhexidine mouth-rinse used as an adjunct to regular oral hygiene in patients with periodontal disease [54]. In this systematic review, patients using chlorhexidine experienced a $33 \%$ reduction in plaque and a $26 \%$ in gingivitis. Chlorhexidine is effective against an array of microorganisms including grampositive and gram-negative bacteria, fungi, yeast and viruses. It is bacteriostatic at low concentration and bactericidal at high concentrations [55]. In a meta-analysis comparing the effect of essential oil mouth-rinses with chlorhexidine, it was found that chlorhexidine was superior to essential oils in terms plaque reduction while there were no significant differences in gingivitis reduction [56]. 


\section{a. Effect on plaque using fluoridated toothpaste as control}

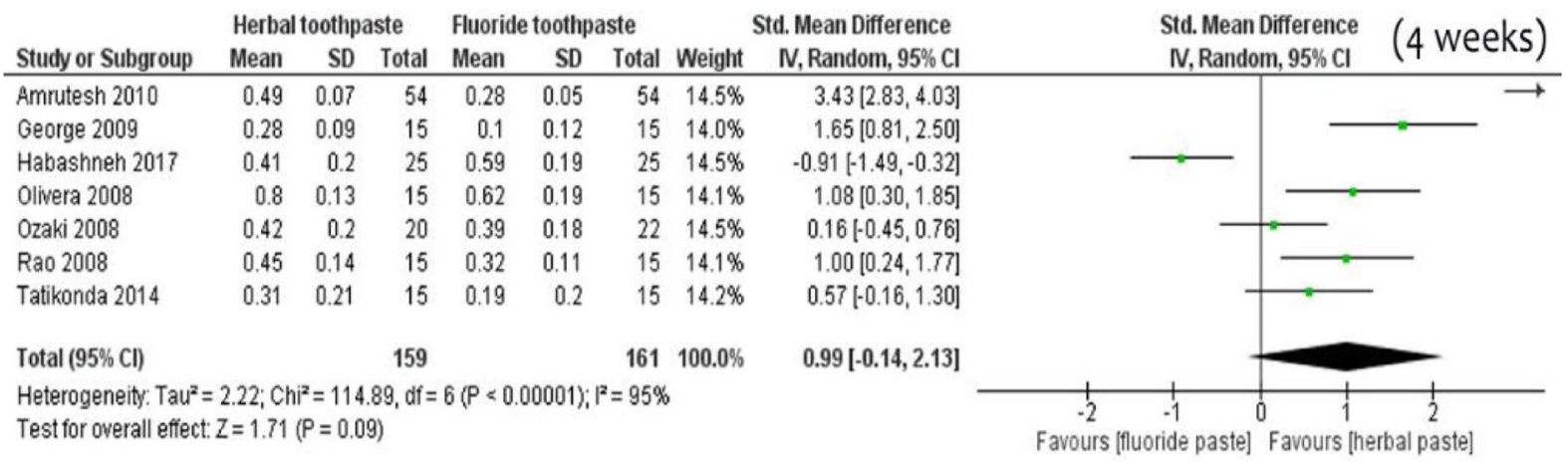

\section{b. Effect on plaque using non-fluoridated toothpaste as control}

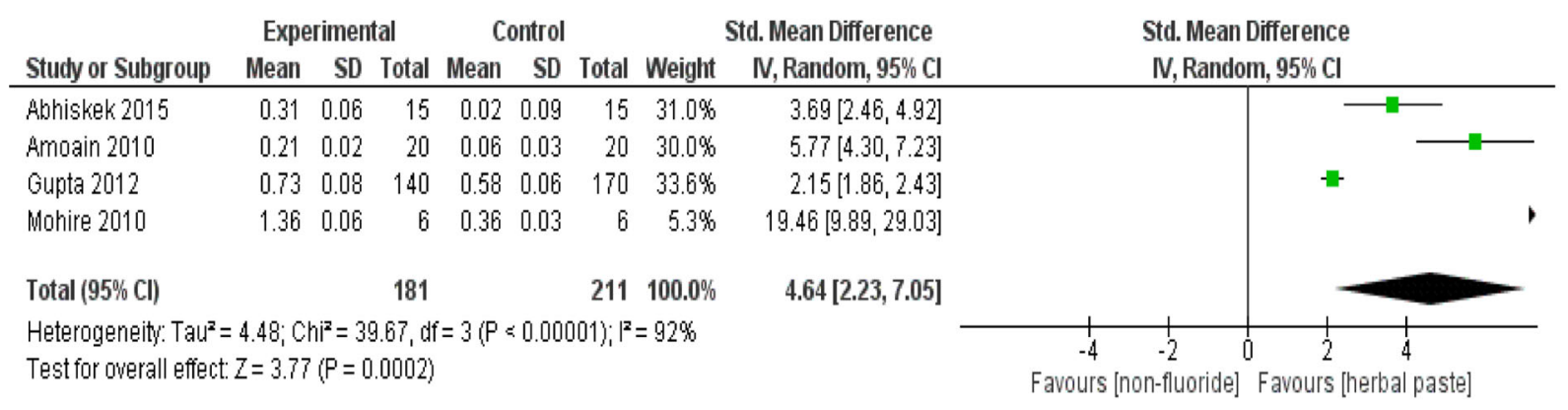

\section{c. Effect on plaque using -. Silness and Loe index scale for assessment}

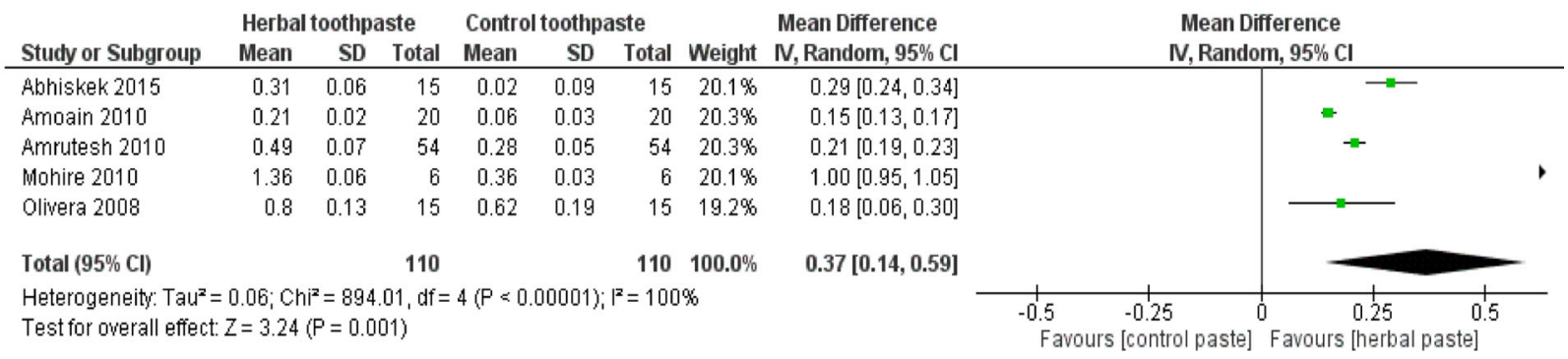

Fig. 3 Subgroup analysis; comparison of herbal toothpaste with non-herbal toothpaste at 4 weeks follow-up $3 \mathbf{a}$. Effect on plaque using fluoridated toothpaste as control $\mathbf{3} \mathbf{b}$. Effect on plaque using non-fluoridated toothpaste as control $3 \mathbf{c}$. Effect on plaque using -. Silness and Loe index scale for assessment

The need for an oral rinse to be retained in the oral cavity to maintain potency over an extended length of time has been debated. An antimicrobial agent needs sufficient substantivity (defined as the persistence of the effect of its active ingredient) to inhibit or kill a microorganism [57]. Chlorhexidine, with a substantivity of 12 $h$, is highly effective, whereas the substantivity of herbal mouth rinses is unknown. Based on the results of this review, there is not enough statistically significant evidence to suggest that herbal oral rinses had a greater effect in reducing gingival index scores or plaque scores. Mouth rinses are generally prescribed for two different conditions; maintenance of oral health in patients with good oral hygiene and to recover from local (gingivitis, periodontitis, surgical treatments, radiotherapy) and systemic (alteration of the immune response, chemotherapy) disorders. Our findings do not support a recommendation for the use of herbal mouth rinses for daily use or for any specific condition, unlike chlorhexidine mouth rinse which is well supported by research. However, taking into consideration the long-term adverse effects with the use of chlorhexidine, conditionally HMR can be recommend as an alternative.

Herbal medicines are plant-derived materials or products with therapeutic properties used in folk medicine, 


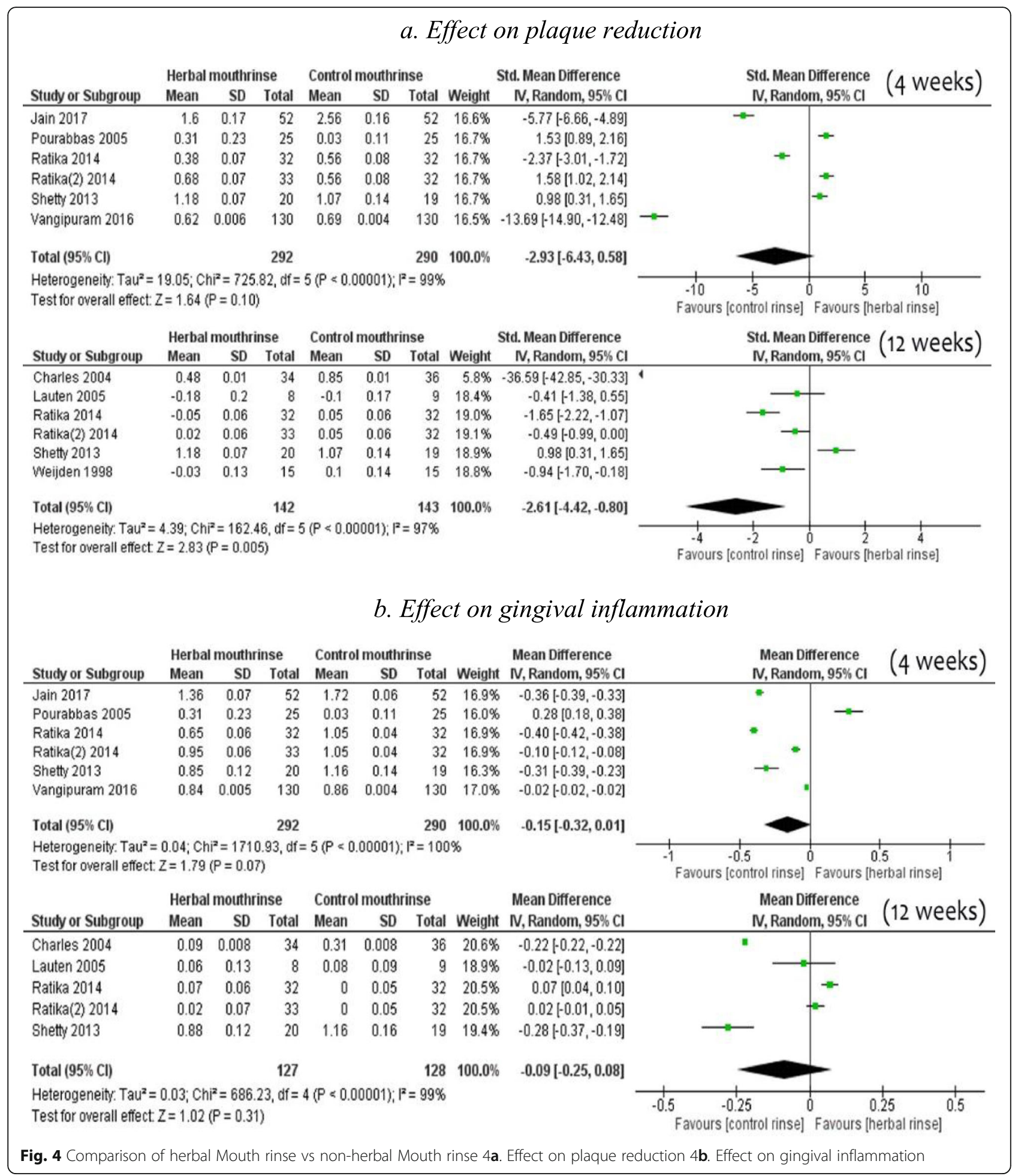

involving both Eastern and Western medical traditions. The use of these products in the prevention and treatment of oral conditions has increased recently and could benefit low socio-economic rural communities especially in low income countries. Herbal extracts have received special attention because they are non-synthetic or "organic" in nature. Consumers who use herbal products often view these products as being safer than products that have "chemicals" although there are reports of allergy/hypersensitivity reactions resulting from herbal and conventional toothpastes. The wide variety of formulations hampers the ability to identify whether a clinical 
outcome is related to the herbal or other active agents. Research on the side effects of these formulations is still lacking. Nevertheless, due to the demand for natural products, there is a thriving market for herbal oral care products.

Herbal toothpastes or mouth rinses should be tested for equivalence in efficacy against the use of a positive control using standard products containing fluoride or chlorhexidine rather than the use of non-fluoride toothpastes or non-chlorhexidine mouth rinses. Future research would benefit from a uniform method of assessment for clinical effectiveness of plaque and gingivitis using these products. Currently, heterogeneity in methodology and evaluation, including the duration of follow-up and assessment is hindering the development of synthesized evidence to determine product effectiveness. Finally, there is a lack of a uniform reporting, including any adverse events associated with the use of experimental herbal products, although reporting standards for RCTs exist (e.g., CONSORT). Reporting standards are very important for clinical information systems where evidence translation solely depends on RCTs. However, RCTs testing the herbal products evaluations poses complex problem for clinical or health information due to variation in comparison of two different system of medicine like western with alternative medicine. So, there is a need for reporting guidelines for herbal molecules product studies, which would enhance the knowledge transformation of the research evidence into policy.

\section{Conclusion}

Herbal toothpaste appears to be equally effective as nonherbal toothpaste, but not superior to fluoride toothpaste. The herbal mouth rinses were found not to be superior to chlorhexidine mouth rinses. The quality of evidence appears to be low/very low to recommend them as a substitute to more conventional OTC oral hygiene products.

\section{Supplementary information}

Supplementary information accompanies this paper at https://doi.org/10. 1186/s12906-020-2812-1.

Additional file $\mathbf{1}$ Figure $\mathbf{S 1}$ Review authors' judgements about each risk of bias item for each included study. Figure S2 Risk of bias graph: review authors' judgements about each risk of bias item presented as percentages across included studies. Table S1 Table S2. List of excluded studies and reasons for exclusion

\section{Abbreviations}

BD: Bruce Dye; CJ: Chandrashekar Janakiram; HMR: Herbal mouth rinse; HTP: Herbal toothpaste; MD: Mean Deviation; NHMR: Non-herbal mouth rinse; NHTP: Non-herbal toothpaste; OTC: Over the Counter; PF: Paul Fontelo; RV: Ramanarayanan Venkitachalam; SMD: Standard Mean Deviations; TI: Timothy lafolla

\section{Acknowledgements}

The authors wish to thank Ms. Alicia Livinski from the NIH Library for her review and comments to this manuscript.

\section{Authors' contributions}

CJ, contributed to the design of the review, data acquisition, data interpretation and analysis and wrote the manuscript; RV, contributed to the statistical analysis, data acquisition and wrote the manuscript; PF contributed to data analysis and critically revised the manuscript; TI contributed to the design data interpretation and critically revised the manuscript; BD contributed to the design of the review, data acquisition, data interpretation and critically revised the manuscript. All authors gave final approval and agree to be accountable to all aspects of the work.

\section{Funding}

This work was supported by the National Institute of Dental and Craniofacial Research (NIDCR) and the Intramural Research Program of the National Institutes of Health (NIH), National Library of Medicine (NLM) and Lister Hill National Center for Biomedical Communications (LHNCBC). Some authors were paid a salary by the $\mathrm{NIH}$.

\section{Availability of data and materials}

" Not applicable".

Ethics approval and consent to participate

The current study was determined exempt from review by the National Institutes of Health Institutional Review Board.

\section{Consent for publication}

"Not applicable".

\section{Competing interests}

The authors have no affiliation with or involvement in any organization or entity with direct financial interest in the subject matter discussed in the manuscript.

\section{Author details}

${ }^{1}$ National Institutes of Health, National Library of Medicine and National Institute of Dental and Craniofacial Research, 31 Center Drive, Suite 4B62, Bethesda, MD 20892-2190, USA. ²Department of Public Health Dentistry, Amrita Vishwa Vidyapeetham, Amrita School of Dentistry, Kochi 682041, India. ${ }^{3}$ National Library of Medicine, National Institutes of Health, 8500 Rockville Pike, Bethesda, MD 20894, USA. ${ }^{4}$ National Institute of Dental and Craniofacial Research, 31 Center Drive, Bethesda, MD 20892-2190, USA.

Received: 13 August 2019 Accepted: 31 December 2019

Published online: 11 February 2020

References

1. Niklaus Lang, Rolf Attstrom, Loe Harald. Proceedings of the European Workshop on Mechanical Plaque Control. United States of America: Quintessence Publishing (IL); 1998.

2. van der Weijden GA, Hioe KPK. A systematic review of the effectiveness of self-performed mechanical plaque removal in adults with gingivitis using a manual toothbrush. J Clin Periodontol. 2005;32(Suppl 6):214-28.

3. Barnett ML. The rationale for the daily use of an antimicrobial mouthrinse. J Am Dent Assoc 1939. 2006 Nov;137 Suppl:16S-21S.

4. Serrano J, Escribano M, Roldán S, Martín C, Herrera D. Efficacy of adjunctive anti-plaque chemical agents in managing gingivitis: a systematic review and meta-analysis. J Clin Periodontol. 2015 Apr 1;42:S106-38.

5. Moran JM. Home-use oral hygiene products: mouthrinses. Periodontol 2000. 2008 Oct 1:48(1):42-53.

6. Teles RP, Teles FRF. Antimicrobial agents used in the control of periodontal biofilms: effective adjuncts to mechanical plaque control? Braz Oral Res. 2009;23(Suppl 1):39-48.

7. Al-Kholani Al. Comparison between the efficacy of herbal and conventional dentifrices on established gingivitis. Dent Res J. 2011;8(2):57-63.

8. Hosamane M, Acharya AB, Vij C, Trivedi D, Setty SB, Thakur SL. Evaluation of holy basil mouthwash as an adjunctive plaque control agent in a four day plaque regrowth model. J Clin Exp Dent. 2014 Dec;6(5):e491-6.

9. Abhishek KN, Supreetha S, Sam G, Khan SN, Chaithanya KH, Abdul N. Effect of Neem containing Toothpaste on Plaque and Gingivitis--A Randomized Double Blind Clinical Trial. J Contemp Dent Pract. 2015 $01 ; 16(11): 880-883$. 
10. Kumar VS, Navaratnam V. Neem (Azadirachta indica): prehistory to contemporary medicinal uses to humankind. Asian Pac J Trop Biomed. 2013;3(7):505-14.

11. Mohammad A. Alzohairy. Therapeutics Role of Azadirachta indica (Neem) and Their Active Constituents in Diseases Prevention and Treatment. Evidence-Based Complementary and Alternative Medicine. 2016;(2016):1-11. https://doi.org/10.1155/2016/7382506

12. Herbal Toothpaste Market 2017 Key Growth Drivers, Challenges, Demand and Upcoming Trends by Forecast to 2023 - ABNewswire - Press Release Distribution Service - Paid Press Release Distribution Newswire [Internet]. Available from: http://www.abnewswire.com/pressreleases/herbaltoothpaste-market-2017-key-growth-drivers-challenges-demand-andupcoming-trends-by-forecast-to-2023_175131.html [cited 201818 Oct]

13. Chen Y, Wong RWK, McGrath C, Hagg U, Seneviratne CJ. Natural compounds containing mouthrinses in the management of dental plaque and gingivitis: a systematic review. Clin Oral Investig. 2014;18(1):1-16.

14. Dhingra K. Aloe vera herbal dentifrices for plaque and gingivitis control: a systematic review. Oral Dis. 2014 Apr;20(3):254-67.

15. Chandra Shekar BR, Nagarajappa R, Suma S, Thakur R. Herbal extracts in oral health care - a review of the current scenario and its future needs. Pharmacogn Rev. 2015;9(18):87-92.

16. Freires $\mid \mathrm{A}$, Rosalen PL. How natural product research has contributed to Oral care product development? A Critical View Pharm Res. 2016;33(6):1311-7.

17. Higgins J, Green S. Cochrane Handbook for Systematic Reviews of Interventions Version 5.1.0 [updated March 2011]. The Cochrane Collaboration, 2011. Available from www.handbook.cochrane.org. [Internet]. Vol. Version 5.1.0. The Cochrane Collaboration, 2011; 2011. Available from: www.handbook.cochrane.org

18. Higgins JPT, Altman DG, Gøtzsche PC, Jüni P, Moher D, Oxman AD, et al. The Cochrane Collaboration's tool for assessing risk of bias in randomised trials. BMJ. 2011 Oct 18;343:d5928.

19. Huedo-Medina T, Sanchez-Meca J, Marin-Martinez F, Botella J. Assessing heterogeneity in meta-analysis: Q statistic or 12 index? CHIP doc [internet]. 2006 Jun 1; Available from: https://opencommons.uconn.edu/chip_docs/19

20. Higgins JPT, Thompson SG. Quantifying heterogeneity in a meta-analysis. Stat Med. 2002 Jun 15:21(11):1539-58

21. Grading quality of evidence and strength of recommendations. BMJ. 2004 Jun 19:328(7454):1490.

22. Ozaki F, Pannuti CM, Imbronito AV, Pessotti W, Saraiva L, de Freitas NM, et al. Efficacy of a herbal toothpaste on patients with established gingivitis-a randomized controlled trial. Braz Oral Res. 2006 Jun;20(2):172-7.

23. de Oliveira SMA, Torres TC, Pereira SL d S, Mota OM de L, Carlos MX. Effect of a dentifrice containing Aloe vera on plaque and gingivitis control. A double-blind clinical study in humans. J Appl Oral Sci Rev FOB. 2008 Aug; 16(4):293-6.

24. Rao S, Avinash S, Rao R, Prahlad S, Mitra SK. A randomized single blind clinical trial to evaluate the safety and efficacy of Himalaya herbal dental cream. Antiseptic. 2008;105(12):601-2.

25. George J, Hegde S, Rajesh KS, Kumar A. The efficacy of a herbalbased toothpaste in the control of plaque and gingivitis: a clinicobiochemical study. Ind J Dent Res Off Publ Indian Soc Dent Res. 2009 Dec;20(4):480-2.

26. Amoain B, Mogadhamnia AA, Mazandharani M, Amoain MM, Mehrmanesh S. The effect of Calendula extract toothpaste on the plaque index and bleeding in gingivitis. Res J Med Plant. 2010:4(3):132-40.

27. Amrutesh S, Malini J, Tandur PS, Patki PS. Clinical evaluation of a nove herbal dental cream in plaque formation: a double-blind, randomized, controlled clinical trial. J Exp Pharmacol. 2010;2:105-9.

28. Mohire NC, Yadav AV. Chitosan-based polyherbal toothpaste: as novel oral hygiene product. Indian J Dent Res Off Publ Ind Soc Dent Res. 2010 Sep;21(3):380-4.

29. Gupta P, Agarwal N, Anup N, Manujunath BC, Bhalla A. Evaluating the antiplaque efficacy of meswak (Salvadora persica) containing dentifrice: a triple blind controlled trial. J Pharm Bioallied Sci. 2012 Oct;4(4):282-5.

30. Tatikonda A, Debnath S, Chauhan VS, Chaurasia VR, Taranath M, Sharma AM Effects of herbal and non-herbal toothpastes on plaque and gingivitis: a clinical comparative study. J Int Soc Prev Community Dent. 2014 Dec; 4(Suppl 2):S126-9.

31. Al Habashneh R, Farasin R, Khader Y. The effect of a triclosan/copolymer/ fluoride toothpaste on plaque formation, gingivitis, and dentin hypersensitivity: A single-blinded randomized clinical study. Quintessence Int Berl Ger 1985. 2017;48(2):123-130.
32. Estafan D, Gultz J, Kaim JM, Khaghany K, Scherer W. Clinical efficacy of an herbal toothpaste. J Clin Dent. 1998;9(2):31-3.

33. Pradeep AR, Agarwal E, Naik SB. Clinical and microbiologic effects of commercially available dentifrice containing aloe vera: a randomized controlled clinical trial. J Periodontol. 2012 Jun;83(6):797-804.

34. SL da S P, YCM P, Bastos TC, PNB A, da Costa FN. Clinical effect of a gel containing Lippia sidoides on plaque and gingivitis control. Eur J Dent. 2013 Jan;7(1):28-34

35. Pourabbas R, Delazar A, ChitsazMT. The effect of German chamomile mouthwash on dental plaque and gingival inflammation. Iran J Pharm Res 2010 Nov 20;0(0):105-109.

36. Shetty PR, Setty SB, Kamat SS, Aldarti AS, Shetty SN. Comparison of the antigingivitis and antiplaque efficacy of the herboral (herbal extract) mouthwash with chlorhexidine and listerine mouthwashes: a clinical study. Pak Oral Dent J. 2013:33(1)

37. Sharma R, Hebbal M, Ankola AV, Murugaboopathy V, Shetty SJ. Effect of two herbal mouthwashes on gingival health of school children. J Tradit Complement Med. 2014;4(4):272-278. https://doi.org/10.4103/2225-4110. 131373

38. Vangipuram S, Jha A, Bhashyam M. Comparative efficacy of aloe vera mouthwash and chlorhexidine on periodontal health: a randomized controlled trial. J Clin Exp Dent. 2016;8(4):e442-7.

39. Jain P, Sontakke P, Walia S, Yadav P, Biswas G, Kaur D. Assessment of the efficacy of licorice versus $0.2 \%$ chlorhexidine oral rinse on plaqueinduced gingivitis: A randomized clinical trial. Indian J Oral Health Res. 2017;3(1):15-8.

40. Van der Weijden GA, Timmer CJ, Timmerman MF, Reijerse E, Mantel MS, van der Velden $U$. The effect of herbal extracts in an experimental mouthrinse on established plaque and gingivitis. J Clin Periodontol. 1998 May:25(5):399-403.

41. Charles CH, Mostler KM, Bartels LL, Mankodi SM. Comparative antiplaque and antigingivitis effectiveness of a chlorhexidine and an essential oil mouthrinse: 6-month clinical trial. J Clin Periodontol. 2004 Oct:31(10):878-84

42. Lauten JD, Boyd L, Hanson MB, Lillie D, Gullion C, Madden TE. A clinical study: Melaleuca, Manuka, Calendula and green tea mouth rinse. Phytother Res PTR. 2005 Nov;19(11):951-7.

43. Löe $H$. The Gingival Index, the Plaque Index and the Retention Index Systems. J Periodontol. 1967 Dec;38(6):Suppl:610-616.

44. Turesky S, Gilmore ND, Glickman I. Reduced plaque formation by the chloromethyl analogue of victamine C. J Periodontol. 1970 Jan;41(1):41-3.

45. Silness J, Loe H. PERIODONTAL DISEASE IN PREGNANCY. II. CORRELATION BETWEEN ORAL HYGIENE AND PERIODONTAL CONDTION. Acta Odontol Scand. 1964 Feb;22:121-35.

46. Albandar JM, Rams TE. Global epidemiology of periodontal diseases: an overview. Periodontol. 2002;29:7-10.

47. Kamath S, Nair R. Red herbal dentifrice [Internet]. US20070116652A1, 2007. Available from: https://patents.google.com/patent/US20070116652A1/en [cited 2018 Mar 8].

48. Southern EN, McCombs GB, Tolle SL, Marinak K. The comparative effects of $0.12 \%$ chlorhexidine and herbal oral rinse on dental plaque-induced gingivitis. J Dent Hyg JDH. 2006;80(1):12.

49. Vahabi S, Najafi E, Alizadeh S. In vitro antimicrobial effects of some herbal essences against oral pathogens. J Med Plants Res. 2011;5(19):4870-8.

50. Shaheen SS, Reddy P, null H, Reddy S, Doshi D, Kulkarni S, et al. Antimicrobial efficacy of ten commercially available herbal dentifrices against specific Oral microflora - in vitro study. J Clin Diagn Res JCDR. 2015 Apr;9(4):ZC42-6

51. Kanth MR, Prakash AR, Sreenath G, Reddy VS, Huldah S. Efficacy of specific plant products on microorganisms causing dental caries. J Clin Diagn Res JCDR. 2016 Dec;10(12):ZM01-3.

52. Seneviratne CJ, Zhang CF, Samaranayake LP. Dental plaque biofilm in oral health and disease. Chin J Dent Res Off J Sci Sect Chin Stomatol Assoc CSA. 2011:14(2):87-94

53. Wu-Yuan CD, Green L, Birch WX. In vitro screening of Chinese medicinal toothpastes: their effects on growth and plaque formation of mutans streptococci. Caries Res. 1990;24(3):198-202.

54. Van Strydonck DAC, Slot DE, Van der Velden U, Van der Weijden F. Effect of a chlorhexidine mouthrinse on plaque, gingival inflammation and staining in gingivitis patients: a systematic review. J Clin Periodontol. 2012 Nov; 39(11):1042-55 
55. Osso D, Kanani N. Antiseptic mouth rinses: an update on comparative effectiveness, risks and recommendations. J Dent Hyg JDH. 2013 Feb;87(1):10-8.

56. Van Leeuwen MP, Slot DE, Van der Weijden GA. Essential oils compared to chlorhexidine with respect to plaque and parameters of gingival inflammation: a systematic review. J Periodontol. 2011. Feb;82(2):174-94.

57. Corbet EF, Tam JO, Zee KY, Wong MC, Lo EC, Mombelli AW, et al.

Therapeutic effects of supervised chlorhexidine mouthrinses on untreated gingivitis. Oral Dis. 1997 Mar;3(1):9-18.

\section{Publisher's Note}

Springer Nature remains neutral with regard to jurisdictional claims in published maps and institutional affiliations.

Ready to submit your research? Choose BMC and benefit from:

- fast, convenient online submission

- thorough peer review by experienced researchers in your field

- rapid publication on acceptance

- support for research data, including large and complex data types

- gold Open Access which fosters wider collaboration and increased citations

- maximum visibility for your research: over $100 \mathrm{M}$ website views per year

At $\mathrm{BMC}$, research is always in progress.

Learn more biomedcentral.com/submissions 